RESEARCH ARTICLE

\title{
A Dilemma about the Mental
}

\author{
Guy Dove* - Andreas Elpidorou**
}

Received: 24 April 2019 / Revised: 8 June 2020 / Accepted: 11 September 2020

Abstract: Physicalism demands an explication of what it means for something to be physical. But the most popular way of providing one-viz., characterizing the physical in terms of the postulates of a scientifically derived physical theory - is met with serious trouble. Proponents of physicalism can either appeal to current physical theory or to some future physical theory (preferably an ideal and complete one). Neither option is promising: currentism almost assuredly renders physicalism false and futurism appears to render it indeterminate or trivial. The purpose of this essay is to argue that attempts to characterize the mental encounter a similar dilemma: currentism with respect to the mental is likely to be inadequate or contain falsehoods and futurism leaves too many significant questions about the nature of mentality unanswered. This new dilemma, we show, threatens both sides of the current debate surrounding the metaphysical status of the mind.

* University of Louisville

(D) https://orcid.org/0000-0003-0470-7006

- Department of Philosophy, University of Louisville, 313 Bingham Humanities Building, Louisville, Kentucky 40292 USA

$\triangle$ guy.dove@louisville.edu

** University of Louisville

(D) https://orcid.org/0000-0001-7317-339X

- Department of Philosophy, University of Louisville 313 Bingham Humanities Building, Louisville, Kentucky 40292 USA

$\bowtie$ andreas.elpidorou@louisville.edu

(c) The Author. Journal compilation (C) The Editorial Board, Organon F.

This article is distributed under the terms of the Creative Commons Attribution-NonCommercial 4.0 International Public License (CC BY-NC 4.0). 
Keywords: Consciousness; materialism; mental; metaphysics; mind; physical; physicalism; reduction; theory.

\section{Introduction}

Physicalism faces what is known as "Hempel's Dilemma." ${ }^{1}$ This dilemma emerges in an attempt to answer the question of how we are to characterize the physical. Not to put too fine a point on it, we can either choose to characterize it in terms of some current theory or some future theory. Those who support the second option typically appeal to a complete and ideal future theory. Neither option seems particularly promising: Choosing current physical theory would almost assuredly make physicalism false or incoherent ${ }^{2}$ and choosing a future theory would seem to render physicalism indeterminate or perhaps trivial. ${ }^{3}$

The purpose of this essay is to argue that a similar dilemma threatens any (non-eliminativist) approach to the mental that attempts to answer significant metaphysical questions about the status of the mind. The idea itself is fairly straightforward: Currentism with respect to the mental is likely to lead to false claims and futurism leaves too many questions unanswered. Insofar as a metaphysical position takes the content of "mental" as either settled or unproblematic, it will falter against the Scylla and Charybdis of this dilemma. The dilemma thus threatens the foundations of the current debate surrounding the metaphysical status of the mind.

1 Hempel (1969; 1980), but see also Chomsky (2000), Crane and Mellor (1990), and Melnyk (1997).

2 If "physical" means the posits of current physics, then physicalism- the view that holds that everything that exists is physical - is false because the inventory of current physics is incomplete. In addition, if understood in terms of current physics, physicalism is likely incoherent because of the existing inconsistencies between the subfields of physics (Wilson 2006)

3 We do not know what such a future theory would look like, nor do we know whether it will end up positing mental entities as fundamental. The fact that it is not possible to determine which of these options - indeterminancy or triviality - will obtain just further highlights the epistemic challenges facing those who embrace the second horn of the dilemma. 
We want to be absolutely clear about what is, and is not, on offer. The dilemma provides neither a positive argument for physicalism nor a refutation of anti-physicalism. The challenge posed by the existence of phenomenal consciousness to physicalist attempts to understand our place in the world does not magically disappear by acknowledging the difficulties that characterizations of the mental face. What the dilemma does is to expose an important blind spot shared by many standard positions in the philosophical discussion of the metaphysical status of the mental. Many participants in this discussion acknowledge the need for precision and nuance when it comes to articulating the ways in which the mental could be related to the physical. It is precisely due to such a concerted and sustained effort to better understand the relationship between the mental and the physical that the literature has been populated by attempts to describe and refine the notions of identity, reduction, supervenience, realization, emergence, and grounding and apply them to the mind-body problem. ${ }^{4}$ Furthermore, both proponents and critics of physicalism have rightly paid much attention to the nature of the physical, asking what it is and how it can be defined. ${ }^{5}$ Unfortunately, however, the very same participants often fail to apply the same kind of rigor and questioning attitude when it comes to the nature of the mental as it figures in the mind-body (or brain) problem. Instead, they typically appeal to intuitive, rough-and-ready characterizations of the mental (qua mental phenomenon) that are thought to suffice for the purposes of examining the metaphysical status of mentality.

There are prima facie reasons to question the adequacy of such characterizations. Consider the case of vitalism. Historically, the phenomenon of life was thought to provide a clear exception to materialism. One factor contributing to vitalism's demise was the inability of its supporters to settle on a precise characterization of vital forces (Mayr 1982). The comparison between consciousness and life has on occasion been dismissed as little more

4 The literature is too expansive to review here. For recent surveys, see Elpidorou (2017), Stoljar (2015), and Tiehen (2018).

5 See, e.g., Bokulich (2011); Dove (2016); Dowell (2006); Melnyk (1997) and (2003); Montero (2001) and (2009); Montero and Papineau (2005); Ney (2008); Spurrett and Papineau (1999); Stoljar (2001); Tiehen (2016); Vicente (2011); Wilson (2006); Witmer (2016); and Worley (2006). 
than a weak argument from analogy (e.g., Chalmers 2003). However, the overall success of physicalist explanations of phenomena that were previously thought to be exceptions to physicalism (Melnyk 2003) and the apparent causal closure of the physical (Papineau 2001) suggest that a more robust account of the mental might be required, just as a richer account of life was required. To put the same point somewhat differently, we need to have reasons that are not shaped by retrospective bias to think that our ideas about the nature of the mental are more solid than our past ideas about life. In the absence of such reasons, the rich, robust, and diverse circumstantial case for physicalism weighs heavily and forces us to take seriously the idea that there might be more to the mental than what our intuitive characterizations of it reveal.

Our aim in this paper is to demonstrate why an appeal to an intuitive, pre-theoretical notion of the mental is insufficient for the purposes of investigating the ontological status of the mental and specifically, of consciousness. Although a comparison between vitalism and physicalism (or between the concept of life and the concept of mental) is suggestive, our case does not rest on that comparison. In fact, we will show that there are reasons internal to the debate pertaining to the ontological status of consciousness that support the need for a rich account of the mental. Because of that, characterizations of the mental-just like those of the physical-face a choice between currentism or futurism.

There has been remarkable progress in both scientific and philosophical investigations of the nature of mentality. Precisely because of such progress, the nature of mentality cannot be assumed to be an unproblematic given. Indeed, we have not reached a settled understanding of the mental yet, nor do we know enough to predict confidently how future theories will describe the mental. But if the meaning of "mental" as this figures in the mind-body problem is unclear, not fully understood, or subject to revision and change, as we will argue that it is, then claims about the relationship between the mental to the physical would also be unclear, not fully understood, or subject to revision and change. According to our view, progress in resolving the mind-body problem is unlikely to take place without first acknowledging that we have only a limited grasp of the nature of mentality. 


\section{Why is this a New Dilemma?}

Given that our dilemma mirrors Hempel's Dilemma to some degree, one might wonder why there has been almost no discussion of it to date. ${ }^{6}$ One reason may be the perception that anti-physicalism and non-physicalist views just do not face the same sort of questions as physicalism. Giving voice to this perception, Levine and Trogdon (2009, 356) write:

A longstanding issue in the philosophy of mind is how to specify the sense of "physical" at issue with materialism. There is no corresponding problem, however, for specifying mentality; mental properties are either conscious properties or intentional properties.

We do not take Levine and Trogdon's remark as proof that there is an agreed-upon characterization of the mental. What the quoted passage suggests instead is that, compared to the task of articulating the physical, describing the mental is an easier task. In the case of the mental, we have some grasp of the essence of mentality: whatever the mental is, it is either the phenomenal or the intentional, or both. Such an understanding of the mental can then serve as our starting point in sketching out the various positions in the debate surrounding the ontological status of the mind and its relationship to the brain, body, and world.

As a matter of actual philosophical practice, there appears to be little disagreement concerning how to broadly define the mental. Although we do not quarrel with the cultural or sociological significance of this claim, we do challenge the notion that such general agreement regarding the mental settles anything. Consider, for example, what would happen if all the philosophers who support physicalism got together and agreed once and for all that the physical should be defined in terms of a commitment to Cartesian corpuscles. Ex hypothesis there would be no disagreement concerning how to characterize the physical. But this would not in any way remove the

${ }_{6} \quad$ The only explicit discussion of this new dilemma that we have found is in (Gillett and Witmer 2001). Tellingly, they dismiss it straight away. They contend that our special epistemic access to mental entities blocks the dilemma. See section 3 below for a discussion of this approach. 
challenge posed by Hempel's Dilemma, which has nothing to do with philosophical agreement and everything to do with accuracy and truth.

Reflecting a kind of philosophical common sense (at least within analytic philosophy), Levine and Trogdon offer a disjunctive characterization of the mental, defining it in terms of either conscious or intentional properties. Because conscious properties are central to so many of the important debates concerning the mental and the physical, we are going to focus on them exclusively in this essay. However, the same arguments that we employ with respect to characterizing the mental in terms of conscious properties can be employed mutatis mutandis to attempts to define it in terms of intentionality. ${ }^{7}$ When we turn to questions concerning the nature of conscious properties, we find that there is a great deal of disagreement concerning how to define them. In other words, all that is accomplished by the disjunctive characterization offered above is that it pushes the problem down a level. Or so we will argue in section 3.

An additional reason for the lack of consideration of our proposed dilemma is that claims about the mental play a different role in the debate over physicalism than our claims about the physical. At a minimum, physicalism rests on the universally quantified claim that all relevant phenomena, including those that we identify as mental, are ultimately physical. Under the typical rough-and-ready formulation, physicalism holds that there is nothing over and above the physical. Hempel's concerns our purported inability to arrive at a characterization of the physical that is able to support this universal claim. In particular, supporters of the dilemma focus on our inability to rule out fundamental mental properties, entities, events, etc. that would seem to violate physicalism. Given this, a strictly analogous dilemma would apply to idealism or what might be called mentalism (the claim that there is nothing over and above the mental). Of course, contemporary adherents of this sort of metaphysical position are hard to find. Instead, anti-physicalists tend to defend the existentially quantified claim that particular mental properties, entities, events, etc. are ultimately not physical ones. Thus, if our dilemma is to be relevant to contemporary debates, it needs to undermine our confidence in our ability to

7 Indeed, we suggest that it will likely be easier to make the case with respect to intentional properties because their theoretical nature is more apparent.

Organon F 28 (4) 2021: 867-895 
characterize mental phenomena in such a way that confirms or disconfirms this more circumscribed metaphysical thesis. In keeping with this, we endeavor to show that our dilemma does indeed undermine confidence in such claims. We argue that neither our current understanding of the mental nor our projectible future understanding is up to the job of settling such metaphysical questions.

The lack of discussion of our proposed dilemma could also be due to the fact that it is a late entry into a crowded field. We already know that the mental presents special philosophical challenges. After all, there is an extensive literature on a number of well-established problems concerning the mental-including the relationship, causal or otherwise, between the mind and body (Jackson 1982; Chalmers 1996; Kim 1998; Libet 1985; Robb and Heil 2013), the hard problem of consciousness (Chalmers 1996), the knowledge argument (Jackson 1982, 1986), and the explanatory gap (Levine 1983; Nagel 1974). Do we really need a new problem concerning the mental? We think that we do. One of the reasons that we think this is that the problem identified in this essay is very different than the other better-known problems. Indeed, it creates conceptual challenges for most of the currently identified problems because they generally view the mental as a serious threat to physicalism or, more broadly, naturalism. Following Jackson (1998), we can categorize most of the traditional puzzles as "location problems" where the core issues are concerned with how to place mental entities or properties in a physical or natural world. These problems generally depend on accepting certain positive claims about the nature of the mental. The new dilemma - which we will heretofore refer to as "DaM" for Dilemma about the Mental - seems to make both the formulation and solution of location problems harder.

Lastly, one might think that DaM does not apply to the mental because of the general perception that the sources of Hempel's original dilemma are the very features of physicalism that supporters of alternative metaphysical accounts of the mental oppose, such as commitments to metaphysical naturalism, reductionism about the mental, ${ }^{8}$ and perhaps some variety of

8 Here we are treating reductionism as the position that holds that the mental is nothing over and above the physical. 
scientism. ${ }^{9}$ Because many metaphysical stances on the mental involve an explicit disavowal of these features,$^{10}$ it is not surprising that their supporters would not worry about an analogous dilemma. ${ }^{11}$ We suggest that this perception is mistaken. Hempel's Dilemma primarily arises from two related elements. The first is a set of reasons to think that our current understanding of the physical is incomplete or inadequate. Certainly the fact that, taken as a whole, contemporary physics is inconsistent counts as a red flag (Wilson 2006). The second is a set of reasons to think that our future understanding will be theoretically transformative in ways that are difficult to appreciate from our current epistemic standpoint. A history consisting of profound theoretical upheavals with respect to our conception of the physical provides an inductive case for the likelihood of radical future theoretical innovation.

We propose that analogs of these two elements - neither of which requires a commitment to naturalism, reductionism, or scientism - are present with respect to the mental. We take our current understanding of the mental to be, at the very least, significantly incomplete or inadequate. And we believe that a future understanding of the mental is likely to be theoretically transformative. Consider, for example, what the possibilities of conscious AI, teleportation, or brain-to-brain communication could teach us about the mind.

\section{Troubles with currentism}

In this section, we set out to accomplish two things. First, we argue that there is actually substantial disagreement concerning the nature of

$9 \quad$ The term scienticism is often used with a negative connotation. However, there has been a recent effort to reclaim the positive sense of this term (e.g., Ladyman and Ross 2007) in much the same way that some philosophers of mind have sought to reclaim the positive sense of reductionism (e.g., Churchland and Churchland 1992). 10 It is important to recognize that this characterization is not universal. For example, Chalmers $(1996,128)$ defends a form of dualism that "...is naturalistic because it posits that everything is a consequence of a network of basic properties and laws."

11 Physicalists, on the contrary, are not particularly focused on finding new problems concerning the mental. 
conscious properties. Second, we contend that this disagreement throws currentism into question.

\subsection{Historical precursors}

Before we get to our argument, we want to acknowledge that our focus on the question of how to characterize conscious properties is not without precedent. We are not the first to highlight the philosophical importance of this issue. Consider a well-known anecdote concerning a public interaction between the philosophers Herbert Feigl and Rudolph Carnap (we are relying on Tim Crane's 2007 recounting of this event). In the course of a talk defending physicalism at UCLA, Feigl admitted that science had yet to provide a physical explanation of the qualia associated with phenomenal experience. Carnap, who was is in the audience, purportedly interrupted Feigl, and the following exchange is supposed to have happened (Crane 2007, 16-17):

Carnap: But Feigl, there is something missing from your lecture. Science is beginning to explain qualia in terms of the alpha factor!

Feigl: Carnap, please tell me: What is the alpha factor?

Carnap: Well, Feigl if you tell me what qualia are, I'll tell you what the alpha factor is.

Whether or not this conversation actually occurred in this manner, we agree with Crane that the point about qualia is well taken. ${ }^{12}$ Too many philosophical discussions about consciousness in general and phenomenal conscious properties in particular rest on the implicit assumption that these phenomena are well understood.

Carnap's rejoinder fits with the general positivist emphasis on the need for philosophers to clearly define their terms, preferably in a way that meshes with the physical sciences. We raise the question of how to characterize conscious properties for different reasons than Carnap: we are not positivists, we are not defending physicalism, and we are not dismissing the

12 In another article, Crane $(2001,170)$ laments: "To have a clear understanding of this problem, we have to have a clear understanding of the notion of qualia. But despite the centrality, it seems to me that there is not a clear consensus about how the term 'qualia' should be understood, and to this extent the contemporary problem of consciousness is not well-posed." 
relevance of conscious properties. We don't even fully agree with Carnap about the facts on the ground. In contrast to his assessment, we think that philosophers have in fact tried to tell us what conscious properties are. Indeed, a lot of work has been done on this topic in the intervening decades. The trouble is that these philosophers often provide very different answers, and their disagreement threatens the first horn of the dilemma.

\subsection{The center will not hold}

To date, we have found only one explicit discussion of something like DaM: Gillett and Witmer (2001) acknowledge the prima facie plausibility of such a dilemma but then argue that it is blocked by our special epistemic access to mental entities. However, special epistemic access is not enough to block DaM because even if we grant that such access exists this would not guarantee that one possesses an adequate understanding of the mental. This seems particularly true of consciousness itself, which of course lies at the center of the disagreement over the status of mental entities. Chalmers $(1996,3)$ himself notes that consciousness, "can be frustratingly diaphanous: in talking about conscious experience, it is notoriously difficult to pin down the subject matter." Indeed, the claim that we have some kind of special or privileged access to our mental states often reduces to one or both of the following claims: (i) Mental states are self-luminous (if a subject is in mental state M, then the subject knows that they are in M) and (ii) Mental states are incorrigible (if a subject believes that they are in mental state $\mathrm{M}$, then they are in M). Neither claim suffices to show that we know the nature of our mental states.

Even if one restricts the mental to (phenomenally) conscious properties, our understanding depends upon our conceptualization of such properties. What this shows is that what we take to be features of conscious properties depends on the nature of our phenomenal concepts (i.e., the concepts that we use when we introspectively examine the phenomenal character of our experience). If the deployment of phenomenal concepts in introspection reveals to us the entire ${ }^{13}$ nature of their referents, then currentism is safe. But

13 If phenomenal concepts reveal only part of the essence of their referents, then we could still be mistaken about the nature of consciousness and qualia. 
why should one accept such a strong claim? The use of phenomenal concepts may reveal only part of the essence of their referents, or it may only reveal accidental features of their referents (ones that allow us to uniquely identify them in the actual world), or it may fail to reveal any features at all. ${ }^{14}$ If any of these three possibilities could be true, then it would undermine currentism.

Moreover, there are very good reasons to be concerned about our current understanding of conscious properties. Their precise nature has been-to echo the quote from Chalmers given above - notoriously difficult to pin down. Responding to the question of what qualia are, Block $(1980,278)$ famously quipped "As Louis Armstrong said when asked what Jazz is, 'If you got to ask, you ain't never gonna get to know'." The trouble is that a number of people have asked and, more importantly, given different answers. ${ }^{15}$ Some categorically deny the existence of qualia at all (Dennett 1991). Others deny that qualia exist where one might think that they should. For instance, Tye and Harman, utilizing the supposition that experiences are transparent or diaphanous, have claimed that qualia are not properties of our visual experiences (e.g., Harman 1990; Tye 2000; cf. Dretske 1995). ${ }^{16}$ Some make the controversial claim that qualia are (or reduce to) the representational contents of our experiences (e.g., Dretske 1995; Lycan 1996). Others hold instead that qualia are intrinsic, non-representational properties of our experiences (e.g, Block 1990; Peacocke 1983). Yet others hold a relational (i.e., direct realist) account of qualia (e.g., Campbell

14 See Nida-Rümelin (2006) and Goff (2011) and critical discussions in Diaz-Leon (2014), Elpidorou (2016) and Trogdon (2016).

15 Our discussion of qualia in this section follows that of Crane (2001). We recommend looking to his paper for a richer and more detailed discussion of the diversity of opinion that exists within the philosophical literature concerning this fundamental notion.

${ }_{16}$ Tye (2017) explains: "[Q]ualia, conceived of as the immediately 'felt' qualities of experiences of which we are cognizant when we attend to them introspectively, do not really exist. The qualities of which we are aware are not qualities of experiences at all, but rather qualities that, if they are qualities of anything, are qualities of things in the world (as in the case of perceptual experiences) or of regions of our bodies (as in the case of bodily sensations). This is not to say that experiences do not have qualia. The point is that qualia are not qualities of experiences." 
2002; Brewer 2011). Finally, there is even disagreement as to what organisms undergo states with qualia. Do insects, for instance, experience qualia?

The aforementioned disagreements are substantial. If we do not know where on the phylogenetic scale qualia start to appear, then we do not have a good understanding of the necessary biological conditions for their existence. If we do not know whether qualia should be individuated narrowly or widely, then we do know what kind of contribution (causal or constitutional) the world makes. And, most importantly, if we cannot agree whether qualia are properties of experiences or not, then it is unclear whether we have really understood the notion of qualia.

But isn't there something intuitively clear and distinctive about our conscious experiences (e.g., Chalmers 2010)? Don't we know that in some sense or another qualia must exist? Don't we know what the redness of the setting sun is? If so, isn't that, admittedly minimal, and pre-theoretical understanding of qualia sufficient to furnish us with a satisfactory account of mentality? The answer, we believe, is simply "No." As noted by both Crane (2001) and Keely (2009), many of the same claims that are made in support of qualia were made about the currently disfavored notion of sense-data. For example, Price in an article from 1932 (quoted by Crane 2001, 175) explains:

The term sense-datum is meant to be a neutral term ... The term is meant to stand for something whose existence is indubitable (however fleeting) something from which all theories of perception ought to start.

Now the mere fact that many of the same, controversial claims made about qualia were made about the earlier notion of sense-data does not in and of itself show that the former are false, but it does suggest that more is needed to settle the matter than a careful self-examination of our inner experience.

Furthermore, the minimal understanding of qualia that one is able to find when one introspects on one's experiences is insufficient to answer the many questions that would allow us to expose the nature of qualia. Can one, simply by focusing on the painfulness of pain or the redness of a Rothko painting, settle whether qualia are properties of experiences or not? Can they determine whether the environment or our bodies make a constitutive contribution to the content of our experience? Can they tell whether it is a possible for a physical and functional duplicate of an acrophobic subject to 
fail to experience fear when they stand near the edge of a tall building? Can they resolve the issue of whether qualia are physical or not? By itself, a minimal, pre-theoretical understanding of qualia, if such a thing exists, cannot settle the nature of mentality. This is evident not only by the vast array of diverging and in some cases contradicting accounts of qualia, all of which seem to appeal to this pre-theoretical notion of qualia (see, e.g., Tye (2017) for an overview), but also by the fact that attempts to specify further the nature of qualia require substantial assumptions about the nature of introspection, awareness, representation, and concepts.

One could argue that our focus on qualia is somewhat dated. In other words, one could possibly claim that our discussion of currentism is not current enough. Current discussions of conscious properties - so the argument might go - are not as reliant on either the term or the concept of qualia. We are willing to grant the possibility that such a shift might be underway. One might even be able to find quantitative evidence for the waning influence of the concept of qualia (tied perhaps to the decreased use of this term). This, however, would not be enough to undermine our general point. What needs to be shown to do this is that significant theoretical disagreement about the precise nature of conscious properties does not exist. We hold the line here and maintain that, if anything, the level of disagreement has increased. In fact, it seems likely that the very reason for the emerging distaste for the term qualia (a distaste which is by no means universal) is a lack of agreement about the nature of qualia. Moreover, it is hard not to see how this purported shift away from qualia is not grist for our mill. After all, if the notion of qualia is currently falling out of favor the way that sense-data fell out of favor decades ago, then we have some inductive reason to question our current understanding. Again, this is not an argument that we will never arrive at a successful theory. More importantly, it is not an attack on the effort to theorize about the nature of conscious properties. Instead, it is merely pointing out there is reason to think that our current understanding is not accurate or secure enough to settle important metaphysical questions.

We propose that the existence of significant disagreement about the very nature of conscious properties impugns our current state of knowledge. This is not a denial of the existence of conscious properties but rather an 
assessment of our current understanding of them. Despite appearances to the contrary, our current understanding of mentality (at least as it is defined relative to conscious properties) is far from complete and likely to be mistaken in significant ways. Future developments in philosophy, biology, neuroscience, and psychology could render many of our beliefs about mentality false. ${ }^{17}$

\section{The prospects of futurism}

Above we argued that our current understanding of mentality leaves much to be desired. Could one characterize the mental in terms of a final and complete theory or account of the mental? Just as any meaningful form of physicalism must avoid positing sui generis non-physical entities, any meaningful and positive account of the character and ontology of the mental must avoid a robust eliminativism in which the mental does not exist. We believe that a futurist approach is fraught with difficulties. Our main contention is that, given our current epistemic standing in regard to mentality, the shape of this final theory or account is severely and problematically (for present purposes) indeterminate. This is due primarily to two facts. First, there are a number of competing theories of the mental that might turn out to be true. Second, most (if not all) of these possible final theories are radically transformative insofar as their success would require a substantial revision of our current understanding of the mental. The question remains: Does this revision amount to a wholesale rejection of the mental as it is currently understood or not? We suggest that we do not know enough about the future outcomes of our theories of mentality to be in a position to make an informed judgment about their content.

Consider for instance the following possible final theories about the mental: emergentism, non-reductive physicalism (e.g., realization), neutral monism, property dualism, panpsychism, or something completely new and

17 Scientific discoveries, e.g., blindsight (Weiskrantz 1980) and the two visual streams hypothesis (Milner and Goodale 2006), and conceptual advances, e.g., the phenomenal/access consciousness distinction (Block 1995) have transformed our understanding of consciousness and thus of mentality. 
unknown. Obviously the last option is a non-starter as a means of avoiding indeterminacy. But all the other ones are also problematic. Indeed, many of the problems that beset a currentist attempt to define the mental also beset these future theories. As we saw in the previous section, our current understanding of conscious properties is at best incomplete. On the one hand, there is significant disagreement about the nature of conscious properties, and on the other hand, any understanding of conscious properties that can serve as the "common denominator" across different positions appears to be incapable of settling substantial questions about the character of the mental. Consequently, any attempt to characterize the mental on the basis of a future theory that utilizes our current understanding of qualia would be problematic insofar as the content of such a future theory is (given our current epistemic perspective) severely indeterminate. We just do not know which of the many competing accounts of the mental we ought to accept, and if we opt for a minimal (or "thin") understanding of the mental, then our future theory will fail to specify the ontological status of the mental. The point is simple: we don't know enough about qualia right now to be able to draw meaningful conclusions concerning how the notion of qualia will be developed in the future.

Finally, it will not work to characterize the mental in terms of a final theory but not specify whether that theory is, e.g., panpsychism, neutral monism, or realization physicalism. Each of them tells us something radically different about the nature of mentality. Put crudely, the first holds that the mental is fundamental, the second holds that fundamentally nothing is mental, and the third holds that the mental exists but only derivatively (it is nothing over and above the physical). The fact that some of our candidates for a final theory of the mental are deeply at odds with each other shows that before we can define the mental by using one of these theories, we have to decide which one is likely to be true. But if philosophical debates about the nature of consciousness are any indication, we are far away from being able to do so. All in all, the prospects of futurism appear to be rather dim. 


\section{Objections and replies}

We have argued that attempts to characterize the mental encounter a dilemma similar to the one faced by physicalists in their efforts to define the physical. Given our contemporary understanding of the mind-including all that we have gathered through our phenomenological experiences, philosophical investigations, and the psychological and brain sciences-neither currentism nor futurism with respect to consciousness and other purportedly non-physical mental properties holds much promise. Recognizing that DaM flies in the face of philosophical conventional wisdom and threatens to upend established philosophical debates concerning the relationship of the mental to the physical, we review some possible objections and offer responses below. The objections share a common theme: the idea that the dilemma, for one reason or another, does not apply to the debate between physicalists and anti-physicalists.

Before getting to these objections though, we want to emphasize what we see as the fundamental force of the dilemma. We suggest that the dilemma throws into question our capacity to answer important metaphysical questions surrounding consciousness and other mental phenomena given our current knowledge. It thus decidedly does not amount to a defense of either physicalism or anti-physicalism. What it does do is threaten the arguments offered in support of either metaphysical position. In other words, we acknowledge that identifying the dilemma does not make consciousness any less mysterious or help us to see how it fits in our world. Indeed, the dilemma demonstrably adds to the mystery. After all, it demonstrates that we know even less we thought we did about conscious properties. DaM in no way forces us to deny the presence of the significant epistemic gap that inspires most of the important philosophical puzzles. Having said this, we need to also point out that DaM becomes an issue for specific formulations of these puzzles. If it obtains, then our epistemic grip on the mental may well be insufficient to affirm the possibility of inverted spectra or philosophical zombies, to arrive at an adequate understanding of the super-scientist Mary, or to outline clearly the hard problem of consciousness. In other words, DaM places pressure on so-called location problems by throwing into question our understanding of what is being located. 


\subsection{Objection \#1}

There is an important asymmetry between the roles that the terms "physical" and "mental" (or "qualia") play in our evaluation of physicalist theories of mind. "Mental" refers to the properties, entities, events, etc. that need to be explained whereas "physical" denotes the set of properties, entities, events, etc. that are meant to be doing the explaining. Because of the role of "physical" we naturally need a precise account of it. However, because of the non-explanatory role of "mental" we do not need nearly as much precision as we need with "physical." All that we need is some rough understanding of mentality - one that perhaps can be given ostensibly: mentality is THAT!

Reply: We suggest that this objection turns on a misunderstanding of the force of the dilemma. To see why, consider the role that Hempel's original dilemma plays in the debate. Few suggest that, because of the dilemma, we should eliminate our everyday notion of physical properties, entities, events, etc. More to the point, few suggest that we should stop doing physics because of the dilemma. What people do suggest is that the dilemma shows that we do not know enough about the ultimate nature of the physical to answer important metaphysical questions - in particular, the question of whether or not mental entities or properties are physical. In an analogous fashion, this new dilemma should not be seen as an attack on our everyday notion of the mental or indeed on our everyday conception of conscious properties. ${ }^{18}$ Nor should it be seen as attempt to preempt philosophical or scientific investigation of these. As was the case with the original dilemma, DaM threatens attempts to settle the relevant metaphysical questions by an appeal to a substantial account of mentality.

Returning to the objection, we can make the issues raised by DaM explicit. We have no problem granting that there are everyday conceptions of phenomenal experience or other mental phenomena that serve as a starting point for philosophical investigation. These phenomena may well serve in some sense as explananda for philosophical explanation (although we would note that in most non-dogmatic areas of human investigation it is not

18 Of course, suggesting that there is an everyday notion of qualia is contentious to say the least. This fact alone seems to offer support to our main position. 
uncommon to modify one's understanding of what is to be explained in the course of developing explanations). ${ }^{19}$ We do not even question that they may raise intriguing metaphysical location problems. We do suggest, though, that accounts of such phenomena that are rich enough to address the relevant metaphysical questions will need to offer a meaningful characterization of their mentality. As Robert van Gulick notes in his discussion of the explanatory gap, "the more we can articulate the structure within the phenomenal realm, the greater the chances for physical explanation; without structure we have no place to attach our explanatory 'hooks"" $(1997,565)$. Thus, attempts to determine whether an aspect of our conscious life can be explained in physical terms must begin with detailed descriptions of that aspect. It is here that the dilemma becomes relevant, for as we argued in section 3, our understanding of the mind appears to be both incomplete and likely to be mistaken in significant ways. Importantly, this problem arises independently of any understanding of the physical. For instance, it would arise within the context of a full-throated idealism where everything that exists is mental.

\subsection{Objection \#2}

Because anti-physicalism is defined in terms of its opposition to physicalism, it is not undermined by DaM.

Reply: We freely admit that DaM arises in the context of positive claims about the nature of mentality. This raises the possibility that an anti-physicalism devoid of such claims could elude its reach. We suggest however that it is very difficult to envision a substantial form of anti-physicalism that is free of positive commitments concerning the character of the mental. Given that many arguments for anti-physicalism depend crucially on observations concerning conscious experience and a number of philosophers of science have questioned the very notion of theory-neutral observation

19 In the case of consciousness, P.S. Churchland (1986), P. M. Churchland (1995), and Flanagan (1992), among others, have argued for a co-evolutionary approach to the problem of consciousness: one that simultaneously examines the problem of consciousness both from the physical (biological, neuronal, or bodily) and the mental (or phenomenal) perspective. 
(Azzouni 2004; Bogen 2016; Chang 2005; Duhem 1906; Hanson 1958; Kuhn 1962), it seems reasonable to suppose that theoretical influences-perhaps implicit ones - may be at work. More importantly, as became apparent in our discussion of the current debates surrounding qualia and consciousness, there are substantial philosophical disagreements about fundamental aspects of mentality. Although these disagreements do not by themselves impugn any particular (anti-physicalist) account, they provide some reason to doubt that we are dealing with straightforward ontological issues that can be resolved by appealing to a body of evidence about which everyone agrees. Furthermore, the debates tend to concern the very nature of the mental. More often than not, they involve specific assertions about mental phenomena. Given this, a successful anti-physicalism likely needs to provide some positive account of the mental, and this is precisely when the dilemma kicks in.

\subsection{Objection \#3}

DaM does not provide support for physicalism.

Reply: We agree. ${ }^{20}$ That was never the point. Indeed, we would go further and claim that DaM creates problems for various forms of physicalism. For instance, many won't work as a means of avoiding DaM because we still need to know what the mental entities are that supervene on, are realized by, or are grounded in the physical. Full-throated forms of eliminitivism (Churchland, 1981; Bickle, 2003) may avoid this problem, but such views have their own challenges.

In addition, DaM undermines the popular strategy of defending physicalism by positing a No Fundamental Mentality constraint (Wilson 2006) or equating the physical with the non-mental (Spurrett and Papineau 1999; Montero 2009; Montero and Papineau 2005). Let's consider the constraint approach first. If we choose our current understanding of the mental, then any No Fundamental Mentality constraint will be trivially true simply because our current understanding of the mental is likely to be false. If we

20 After all, physicalism still faces Hempel's original dilemma. For discussion and proposed solutions see Dove (2016); Elpidorou and Dove (2018); Hempel (1980); Ney (2008); Prelevic (2017); and van Fraassen (2002). 
choose some future complete and ideal theory, then the proposed constraint is going to be empty. Similar problems face the stratagem of equating the physical with the non-mental. More generally, DaM further muddies the water with respect to the question of whether or not a complete physics contains fundamental mental entities.

\subsection{Objection \#4}

Just as Hempel's Dilemma turns on an appeal to theories of the physical, DaM requires an appeal to theories of the mental. This is a problem for DaM because we do not have - or need - analogous theories of the mental. To the extent that a philosophical position avoids an appeal to theories of the mental, it avoids the dilemma.

Reply: Not surprisingly, we think that it is harder to avoid theoretical claims about the mental than this objection presupposes, but we maintain that the objection fails even if we leave this presupposition unchallenged. DaM concerns our lack of access to characterizations of the mental that are rich enough to settle important metaphysical questions. Avoiding theories of the mental does not get us out of this bind. We still have reason to think that characterizations based on our current understanding of the mental are insufficient and that we know too little about future characterizations to draw significant conclusions. Indeed, the situation appears to be worse than it is with regard to the physical. For instance, some supporters of physicalism have argued that we know enough about current physics to be confident that the posits of a complete and ideal future physical theory will exclude irreducible mental entities (e.g., Bokulich 2011; for reviews see Dove 2016; Ney 2008; Stoljar 2015). Yet, in the case of the mental, there is little indication that we know enough about what a future account of the mental would look like to offer a sufficiently rich characterization of the mental. A lack of access to theories of the mental would only exacerbate this problem.

In the end, the real impetus behind this objection would seem to be a conviction that our current understanding of the mental is rich enough to do the relevant philosophical work. We have already provided reasons to think that it is not. Whether or not one is convinced by our arguments on this front, it is clear that simply avoiding theories of the mental does not circumvent the dilemma. 


\subsection{Objection \#5}

Even if theories of the mental are relevant, most of our current theories are not about the mental itself but rather the metaphysical status of the mental with respect to the physical. ${ }^{21}$ In other words, our so-called theories of the mental are not theories about mental phenomena the way that physical theories are about physical phenomena. Because of this, the dilemma fails to emerge in the first place.

Reply: We have two responses to offer. First, while we acknowledge that there are theories of the mental that focus primarily on answering questions concerning the relationship of the mental to the physical, it is clear that not all of them are content to do only that. For instance, both proponents of naturalistic dualism (Chalmers 1996) and panpsychism (see various essays in Seager 2020) have sought to offer substantive, positive accounts of the mental.

Second, even if we were to grant that most theories of the mental are primarily interested in investigating the relationship of the mental to the physical, we maintain that it is difficult to answer these questions without answering fundamental questions about the nature of mental phenomena themselves. In order to see why this is the case, we need to consider the two horns of our dilemma.

Let's begin with the first horn of the dilemma. In our discussion, we highlighted the disagreement that exists with regard to fundamental questions concerning the nature of qualia. These questions were not limited to the relationship of qualia to the physical. Instead, they often concern important details about qualia themselves, addressing such issues as whether they exist at all, how they are introspectively revealed to us, whether they are simple or complex, what experiential modalities give rise to them, and what sort of creatures experience them. What is important to note isn't merely the existence of this disagreement, but also the fact that the manner in which we might resolve these theoretical disagreements has clear

${ }^{21}$ We thank an anonymous reviewer for pointing out this possible objection. As they succinctly put it, theories of the mental "are not about the mental the way that fluid mechanics is about fluids, they are about the relationship between the mental and the physical." 
implications regarding the metaphysical status of the mental and its relationship to the physical. After all, much of the recent debate regarding the metaphysics of consciousness seems to turn on whether the nature of qualia is somehow revealed to us through introspection. ${ }^{22}$

Now consider the second horn of the dilemma. In outlining the problems with futurism, we did note that positions such as dualism, neutral monism, and panpsychism promise to be transformative. We also suggested that it would be hard to offer substantial versions of these positions without making significant claims about the nature of mental phenomena in and of themselves, but here we don't need this claim to defeat the objection. If the objector is right that contemporary theories of the mental merely address its relationship to the physical, then such theories would provide no help at all to futurism. They wouldn't even address the issues raised in the context of currentism.

\section{Conclusion}

In this essay we have argued that our understanding of the mental faces a similar (but not completely analogous) dilemma to the one facing our understanding of the physical. Our defense of this involved three steps. First, we outlined the reasons why this dilemma may have been overlooked or quickly dismissed. We argued that these reasons are insufficient and provided initial motivation for thinking that the dilemma might obtain. Second, we demonstrated that both horns of the dilemma are problematic: currentism with respect to mental is likely to be at least incomplete or inadequate, and futurism remains indeterminate. Third, we defended the dilemma against several deflationary objections. If we are right, then philosophers interested in metaphysical questions surrounding the mental need to take our dilemma into account.

22 See, e.g., Balog (2012); Chalmers (2007); Diaz-Leon (2014); Elpidorou (2015) and (2016); Goff (2011); Hill \& McLaughlin (1999); Levin (2007); Levine (2007); Loar (1997); Nida-Rümelin (2006); Papineau (2002) and (2007); Schroer (2010), Stoljar (2005); Sturgeon (1994); Sundström (2011); Trogdon (2016). 
It is instructive to compare our position to Stoljar's (2006) epistemic view on consciousness, namely, the view according to which the reason why consciousness appears to be other than physical is because we are ignorant of some non-experiential but experience-relevant truths. Unlike Stoljar we do not use our current ignorance about the nature of qualia or consciousness as a way to disarm traditional anti-physicalist objections. Nor do we insist that our ignorance is due to an elusive set of non-experiential but experience-relevant truths. To hold that the only truths about consciousness that escape us are non-experiential is to accept that our present understanding of (phenomenal) consciousness is more or less complete. DaM denies this assumption. Thus, if we are correct to insist that DaM is a problem, then our ignorance is larger than it is commonly assumed. The bad news is that we do not know as much as we think we do. The good news is that such an admission of ignorance opens up the possibility for new and exciting prospects on mentality in general and on consciousness in particular. A more complete understanding of the mental could render some of the pesky epistemic arguments against physicalism pseudo-problems. Or it could conversely show that physicalism is an unattainable position. So, while DaM may not resolve traditional philosophical puzzles, it may succeed in transforming them. At the very least, it is a call to action to seek a more philosophically and empirically robust account of the mental.

\section{References}

Azzouni, Jody. 2004. "Theory, Observation, and Scientific Realism." British Journal for the Philosophy of Science 55 (3): 371-92. https://doi.org/10.1093/bjps/55.3.371

Bickle, John. 2003. Philosophy and Neuroscience: A Ruthlessly Reductive Account. Dordrecht: Kluwer Academic Publishers. https://doi.org/10.1007/978-94-010-0237-0

Balog, Katalin. 2012. "Acquaintance and the Mind-body Problem." In New Perspectives on Type Identity: The Mental and the Physical, edited by Simone Gozzano, and Christopher S. Hill, 16-42. Cambridge, UK: Cambridge University Press. https://doi.org/10.1017/CBO9780511687068.002

Block, Ned. 1980. "Troubles with Functionalism." In Readings in the Philosophy of Psychology, vol. 1, edited by Ned Block, 268-306. Cambridge: Harvard University Press. 
Block, Ned. 1990. "Inverted Earth." Philosophical Perspectives 4: 53-79. https://doi.org/10.2307/2214187

Block, Ned. 1995. "On a Confusion about a Function of Consciousness." Behavioral and Brain Sciences 18 (2): 227-47. https://doi.org/10.1017/S0140525X00038474

Bogen, Jim. 2016. "Empiricism and After." In The Oxford Handbook of Philosophy of Science, edited by Paul Humphreys, 779-95. Oxford, UK: Oxford University Press. https://doi.org/10.1093/oxfordhb/9780199368815.013.12

Bokulich, Peter. 2011. "Hempel's Dilemma and the Domain of Physics." Analysis 71(4): 646-51. https://doi.org/10.1093/analys/anr087

Brewer, Bill. 2011. Perception and its Objects. Oxford: Oxford University Press. https://doi.org/10.1093/acprof:oso/9780199260256.001.0001

Campbell, John. 2002. Reference and Consciousness, Oxford: Clarendon Press. https://doi.org/10.1093/0199243816.001.0001

Chalmers, David J. 1996. The Conscious Mind: In Search of a Fundamental Theory. Oxford: Oxford University Press.

Chalmers, David J. 2003. "Consciousness and Its Place in Nature." In The Blackwell Guide to Philosophy of Mind, edited by Stephen P. Stich, and Ted A. Warfield, 102-42. Malden, MA: Blackwell Publishing. Revised version in Chalmers, 2010, 103-40. https://doi.org/10.1002/9780470998762.ch5

Chalmers, David J. 2007. "Phenomenal Concepts and the Explanatory Gap." In Phenomenal Concepts and Phenomenal Knowledge: New Essays on Consciousness and Physicalism, edited by Torin Alter, and Sven Walter, 167-94. Oxford, UK: Oxford University Press. https://doi.org/10.1093/acprof:oso/9780195171655.003.0009

Chalmers, David J. 2010. The Character of Consciousness. Oxford: Oxford University Press. https://doi.org/10.1093/acprof:oso/9780195311105.001.0001

Chang, Hasok. 2005. "A Case for Old-fashioned Observability, and a Reconstructive Empiricism." Philosophy of Science 72 (5): 876-87. https://doi.org/10.1086/508116

Chomsky, Noam. 2000. New Horizons in the Study of Language and Mind, Cambridge: Cambridge University Press. https://doi.org/10.1017/CBO9780511811937

Churchland, Paul M. 1995. The Engine of Reason, the Seat of the Soul. Cambridge, MA: MIT Press.

Churchland, Paul M., and Patricia S. Churchland. 1992. "Intertheoretic Reduction: A neuroscientist's Field Guide." In Neurophilosophy and Alzheimer's Disease, edited by Yves Christen, and Patricia S. Churchland, 18-29. Berlin: Springer. https://doi.org/10.1007/978-3-642-46759-2_3

Churchland, Patricia S. 1986. Neurophilosophy. Cambridge, MA: MIT Press. 
Crane, Tim. 2001. "The Origins of Qualia." In History of the Mind-Body Problem, edited by Tim Crane, Sarah Patterson, 164-94. London: Routledge.

Crane, Tim. 2007. "Knowledge of the Mind and Knowledge of the Brain." $3^{\text {rd }} A n$ nual Brain $\&$ Mind Lecture, University of Copenhagen.

http://www.timcrane.com/uploads $/ 2 / 5 / 2 / 4 / 25243881 /$ knowledge_of_mind_and_knowledge_of_brain.pdf

Crane, Tim, and D. Hugh Mellor. 1990. "There is No Question of Physicalism." Mind 90: 185-206.

Diaz-Leon, Esa. 2014. "Do A Posteriori Physicalists Get Our Phenomenal Concepts wrong?" Ratio 27 (1): 1-16. https://doi.org/10.1111/rati.12018

Dennett, Daniel C. 1991. Consciousness Explained. London: Little, Brown \& Co.

Dretske, Fred I. 1995. Naturalizing the Mind, Cambridge, MA: MIT Press, Bradford Books.

Dove, Guy. 2018. "Redefining Physicalism." Topoi 37: 513-22. https://doi.org/10.1007/s11245-016-9405-0

Dowell, Janice L. 2006. "The Physical: Empirical, Not Metaphysical." Philosophical Studies 131 (1): 25-60. https://doi.org/10.1007/s11098-006-6641-y

Duhem, Pierre Maurice Marie. 1914/1954. The Aim and Structure of Physical Theory. Translated by P. W. Wiener. Princeton, NJ: Princeton University Press.

Elpidorou, Andreas. 2017. "Introduction: The Character of Physicalism." Topoi (37): 435-55. https://doi.org/10.1007/s11245-017-9488-2

Elpidorou, Andreas. 2015. "Phenomenal Concepts." In Oxford Bibliographies in Philosophy, edited by Duncan Pritchard. New York: Oxford University Press. https://doi.org/10.1093/OBO/9780195396577-0254

Elpidorou, Andreas. 2016. "A Posteriori Physicalism and Introspection." Pacific Philosophical Quarterly 97 (4): 474-500. https://doi.org/10.1111/papq.12068

Elpidorou, Andreas, and Guy Dove. 2018. Consciousness and Physicalism: A Defense of a Research Program. New York: Routledge.

https://doi.org/10.4324/9781315682075

Feyerabend, Paul K. 1959/1985. "An Attempt at a Realistic Interpretation of Experience." In Realism, Rationalism, and Scientific Method: Philosophical Papers I, 17-36. Cambridge, UK: Cambridge University Press.

https://doi.org/10.1017/CBO9781139171526.003

Flanagan, Owen J. 1992. Consciousness Reconsidered. Cambridge, MA: MIT Press.

Gillett, Carl, and D. Gene Witmer. 2001. "A 'Physical' Need: Physicalism and the Via Negativa." Analysis 61 (272): 302-09. https://doi.org/10.1111/14678284.00309

Goff, Philip. 2011. "A Posteriori Physicalists Get Our Phenomenal Concepts Wrong." Australasian Journal of Philosophy 89 (2): 191-209. https://doi.org/10.1080/00048401003649617 
Hanson, Norwood Russell. 1958. Patterns of Discovery. Cambridge, UK: Cambridge University Press.

Harman, Gilbert, 1990, "The Intrinsic Quality of Experience." In Philosophical Perspectives, vol. 4, edited by James Tomberlin, 31-52. Atascadero, CA: Ridgeview Publishing Company. https://doi.org/10.2307/2214186

Hempel, Carl G. 1969. "Reduction: Ontological and Linguistic Facets." In Philosophy, Science and Method: Essays in Honor of Ernest Nagel, edited by Patrick Suppes, Sidney Morgenbesser, and Morton Gabriel White, 179-99. New York: St. Martin's Press.

Hempel, Carl G. 1980. "Comments on Goodman's Ways of Worldmaking." Synthese 45: 139-99. https://doi.org/10.1007/BF00413558

Hill, Christopher S., and Brian P. McLaughlin. 1999. "There Are Fewer Things in Reality Than Are Dreamt of in Chalmers's Philosophy". Philosophy and Phenomenological Research 59: 445-54. https://doi.org/10.2307/2653682

Jackson, Frank. 1982. "Epiphenomenal Qualia.” Philosophical Quarterly 32 (127): 127-36. https://doi.org/10.2307/2960077

Jackson, Frank. 1986. "What Mary didn't know." The Journal of Philosophy 83 (5): 291-95. https://doi.org/10.2307/2026143

Jackson, Frank. 1998. From Metaphysics to Ethics: A Defence of Conceptual Analysis. Oxford, UK: Oxford University Press. https://doi.org/10.1093/0198250614.001.0001

Keeley, Brian L. 2009. "The Early History of the Quale and Its Relation to the Senses." In Routledge Companion to Philosophy of Psychology, edited by Sarah Robins, John Symons, and Paco Calvo, 71-89. London, UK: Routledge.

Kim, Jaegwon. 1998. Physicalism, or Something Near Enough. Princeton, NJ: Princeton University Press.

Kuhn, Thomas S. 1962/1996. The Structure of Scientific Revolutions, Chicago, IL: University of Chicago Press.

Ladyman, James, and Don Ross. 2007. Every Thing Must Go: Metaphysics Naturalized. Oxford: Oxford Univeristy Press. https://doi.org/10.1093/acprof:oso/9780199276196.001.0001

Levin, Janet. 2007. "What is a phenomenal concept?" In Phenomenal Concepts and Phenomenal Knowledge: New Essays on Consciousness and Physicalism, edited by Torin Alter, and Sven Walter, 87-110. New York, NY: Oxford University Press. https://doi.org/10.1093/acprof:oso/9780195171655.003.0006

Levine, Joseph. 1983. "Materialism and Qualia: The Explanatory Gap." Pacific Philosophical Quarterly 64 (4): 354-61. https://doi.org/10.1111/j.14680114.1983.tb00207.x

Levine, Joseph. 2007. "Phenomenal Concepts and the Materialist Constraint." In Phenomenal Concepts and Phenomenal Knowledge: New Essays on 
Consciousness and Physicalism, edited by Torin Alter, and Sven Walter, 81108. New York, NY: Oxford University Press. https://doi.org/10.1093/acprof:oso/9780195171655.003.0008

Levine, Joseph, and Kelly Trogdon. 2009. "The Modal Status of Materialism." Philosophical Studies 145 (3): 351-362. https://doi.org/10.1007/s11098008-9235-Z

Libet, Benjamin. 1985. "Unconscious Cerebral Initiative and the Role of Conscious Will in Voluntary Action." Behavioral and Brain Sciences 8: 529-39.

https://doi.org/10.1017/S0140525X00044903

Loar, Brian. 1997. "Phenomenal states." In The Nature of Consciousness: Philosophical Debates, edited by Ned Block, Owen Flanagan, and Güven Güzeldere, 597-616. Cambridge, MA: MIT Press.

Lycan, William G. 1996. Consciousness and Experience. Cambridge, MA: MIT Press.

Mayr, Ernst. 1982. The Growth of Biological Thought: Diversity, Evolution, and Inheritance. Cambridge, MA: Harvard University Press.

Melnyk, Andrew. 2003. A Physicalist Manifesto: Thoroughly Modern Materialism. Cambridge: Cambridge University Press. https://doi.org/10.1017/CBO9780511498817

Melnyk, Andrew. 1997. "How to Keep the 'Physical' in Physicalism." Journal of Philosophy 94: 622-37. https://doi.org/10.2307/2564597

Milner, David, and Mel Goodale. 2006. The Visual Brain in Action. Oxford: Oxford University Press. https://doi.org/10.1093/acprof:oso/9780198524724.001.0001

Montero, Barbara. 2001. "Post-Physicalism." Journal of Consciousness Studies 8: 61-80.

Montero, Barbara. 2009. "What is the Physical?" In Oxford Handbook of the Philosophy of Mind, edited by Brian McLaughlin, Ansgar Beckermann, and Sven Walter. Oxford: Oxford University Press. https://doi.org/10.1093/oxfordhb/9780199262618.003.0010

Montero, Barbara, and David Papineau. 2005. "A Defense of the via Negativa Argument for Physicalism." Analysis 65(3): 233-37. http://www.jstor.org/stable/3329031

Nagel, Thomas. 1974. "What Is It Like to Be a Bat?" The Philosophical Review 83(4): 435-50. https://doi.org/10.2307/2183914

Ney, Alyssa. 2008. "Defining Physicalism." Philosophy Compass 3(5): 1033-48. https://doi.org/10.1111/j.1747-9991.2008.00163.x

Nida-Rümelin, M. 2006. "Grasping Phenomenal Properties". In Phenomenal Concepts and Phenomenal Knowledge: New essays on Consciousness and Physicalism, edited by Torin Alter, and Sven Walter, 309-38. Oxford, UK: 
Oxford University Press. https://doi.org/10.1093/acprof:oso/9780195171655.003.0013

Papineau, David. 2001. "The Rise of Physicalism." In Physicalism and Its Discontents, edited by Carl Gillett, and Barry Loewer, 3-36. Cambridge, UK: Cambridge University Press. https://doi.org/10.1017/CBO9780511570797.002

Papineau, David. 2002. Thinking About Consciousness. Oxford, UK: Oxford University Press. https://doi.org/10.1093/0199243824.001.0001

Papineau, David. 2007. "Phenomenal and perceptual concepts." In Phenomenal Concepts and Phenomenal Knowledge: New Essays on Consciousness and Physicalism, edited by Torin Alter, and Sven Walter, 111-44. Oxford, UK: Oxford University Press. https://doi.org/10.1093/acprof:oso/9780195171655.003.0007

Peacocke, Christopher. 1983. Sense and Content. Oxford: Oxford University Press.

Robb, David, and John Heil. 2014. "Mental Causation." In The Stanford Encyclopedia of Philosophy (Spring 2014 Edition), edited by Edward N. Zalta., et al. https://plato.stanford.edu/archives/spr2014/entries/mental-causation/

Seager, William E., ed. 2019. The Routledge Handbook of Panpsychism. New York, NY: Routledge. https://doi.org/10.4324/9781315717708

Schroer, Robert. 2010. "Where's the Beef? Phenomenal Concepts as both Demonstrative and Substantial." Australasian Journal of Philosophy 88 (3): 505-22. https://doi.org/10.1080/00048400903143861

Spurrett, David, and David Papineau. 1999. "A Note on the Completeness of 'Physics'." Analysis 59: 25-29. https://doi.org/10.1093/analys/59.1.25

Stoljar, Daniel. 2001. "Two Conceptions of the Physical." Philosophy and Phenomenological Research 62 (2): 253-81. https://doi.org/10.1111/j.19331592.2001.tb00056.x

Stoljar, Daniel. 2005. "Physicalism and Phenomenal Concepts." Mind E Language 20 (5): 469-95. https://doi.org/10.1111/j.0268-1064.2005.00296.x

Stoljar, Daniel. 2006. Ignorance and Imagination: The Epistemic Origin of the Problem of Consciousness. Oxford, UK: Oxford University Press. https://doi.org/10.1093/0195306589.001.0001

Stoljar, Daniel. 2015. "Physicalism." In The Stanford Encyclopedia of Philosophy (Winter 2017 Edition), edited by Edward N. Zalta., et al. https://plato.stanford.edu/archives/win2017/entries/physicalism/

Sturgeon, Scott. 1994. "The Epistemic View of Subjectivity." The Journal of Philosophy 91 (5): 221-35. https://doi.org/10.2307/2940751

Sundström, Pär. 2011. "Phenomenal Concepts." Philosophy Compass 6 (4): 267-81. https://doi.org/10.1111/j.1747-9991.2011.00384.x

Tiehen, Justin. 2018. "Physicalism." Analysis, 78 (3): 537-51.

https://doi.org/10.1093/analys/any037

Organon F 28 (4) 2021: 867-895 
Tiehen, Justin. 2016. "Physicalism Requires Functionalism: A New Formulation and Defense of the Via Negativa." Philosophy and Phenomenological Research 92 (2): 3-24. https://doi.org/10.1111/phpr.12279

Trogdon, Kelly. 2016. "Revelation and physicalism." Synthese, 1-22. https://doi.org/10.1007/s11229-016-1055-7

Tye, Michael. 2000. Consciousness, Color, and Content. Cambridge, MA: MIT Press.

Tye, Michael. 2017. "Qualia." In The Stanford Encyclopedia of Philosophy (Winter 2017 Edition), edited by Edward N. Zalta., et al. https://plato.stanford.edu/archives/win2017/entries/qualia/

Van Fraassen, Bas C. 2002. The Empirical Stance. New Haven: Yale University Press.

Vicente, Agustín. 2011. "Current Physics and "The Physical." British Journal for the Philosophy of Science 62 (2): 393-416. https://doi.org/10.1093/bjps/axq033

Weiskrantz, L. 1986. Blindsight: A Case Study and Implications. Oxford: Oxford University Press. https://doi.org/10.1093/acprof:oso/9780198521921.001.0001

Wilson, Jessica. 2006. "On Characterizing the Physical." Philosophical Studies 131: 61-99. https://www.jstor.org/stable/25471799

Witmer, D. Gene. 2016. "Physicality for Physicalists." Topoi (37): 457-72. https://doi.org/10.1007/s11245-016-9415-y

Worley, Sara. 2006. "Physicalism and the Via Negativa." Philosophical Studies 131: 101-26. https://doi.org/10.1007/s11098-005-5985-Z 